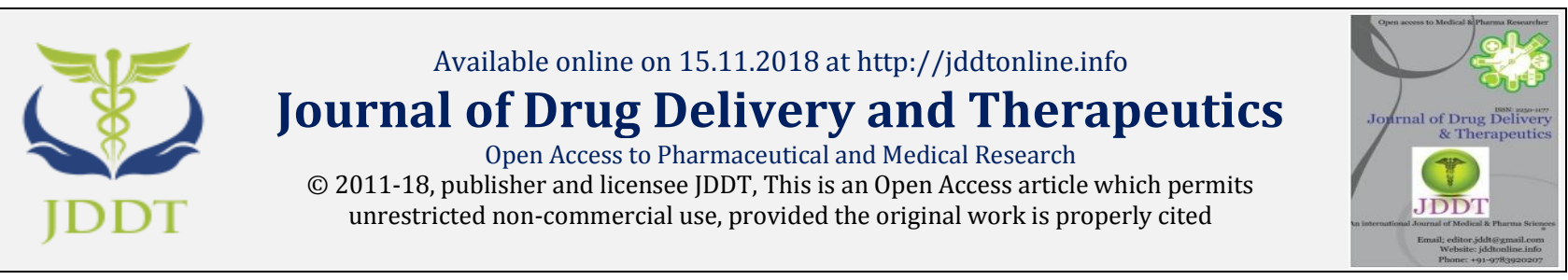

Open 2 Access

Research Article

\title{
Formulation Development to Enhance the Solubility of Metoclopramide Base Drug by Solid Dispersion and Evaluation of Transdermal Film.
}

\author{
Mukhopadhyay Goutam1*, Mukhopadhyay Rahul2, Mukhopadhyay Ankita ${ }^{3}$, Kundu Shymodip 4, Banerjee \\ Shreya $^{4}$, Manna Debasmita5 , Sarkar Argha4 ${ }^{4}$, Nazar Tarique ${ }^{4}$, Sarkar Srotoswini ${ }^{4}$, Bala Sauris ${ }^{4}$ \\ ${ }^{1}$ Associated Professor, Department of Pharmaceutical Technology, BCDA College of Pharmacy \& Technology, 78, Jessore Road(S), Kolkata- \\ 700127 \\ ${ }^{2}$ Assistant Professor, Department of Pharmaceutical Technology, Brainware university, 398, Ramkrishnapur Road, Barasat, Kolkata-700125. \\ ${ }^{3}$ Assistant Professor, Department of Pharmacy, BCDA College of Pharmacy \& Technology, 78, Jessore Road(S), Kolkata-700127. \\ ${ }^{4}$ Student, Department of Pharmacy, BCDA College of Pharmacy \& Technology, 78, Jessore Road(S), Kolkata-700127 \\ ${ }^{5}$ Student, Department of Pharmacy, NSHM Knowledge campus, 124 BL Saha Road, Kolkata-700053.
}

\section{ABSTRACT}

Aims \& Objectives: The present work deals with the modification of controlled release dosage form of poorly water soluble drug (Metoclopramide hydrochloride) in order to improve the bioavailability and to control drug release for a longer period of time by the aid of solid dispersion.

Methods: Various binary combination of MET-solid dispersion was prepared with different carriers such as HP $\beta$ CD, PVP K30 and PLX-188 by solvent evaporation technique and then the aqueous solubility, dissolution study and phase solubility study was performed. DSC analysis is performed to carry out for metoclopramide loaded solid dispersion, physical mixture \& also for pure drug to analyze the crystalline and amorphous nature of compounds.

Results and Discussion: The saturation solubility of Metoclopramide with various carriers at different $\mathrm{pH}$ was performed and found that in pH 5.5 (solubility is $5553.2 \mu \mathrm{g} / \mathrm{ml}), \mathrm{pH} 6.8(3363.3 \mu / \mathrm{ml}), \mathrm{pH} 7.4(1367.3 \mu \mathrm{g} / \mathrm{ml})$ at $37^{\circ} \mathrm{C}$. In dissolution study of solid dispersion (5:1) of different carriers in DDW, the Cumulative \% dissolution is found in the order of PVP K30>PLX-Met>HP 3 CD-Met \& in $\mathrm{pH} 7.4$, in the order of PLX-Met>PVP K30>HPßCD-Met. DSC thermogram of Metoclopramide base showed a sharp endothermic peak at its melting point $\left(147^{\circ} \mathrm{C}\right)$ which exhibits in crystalline form complying with that of Metoclopramide hydrochloride form, melting point was found to be $85^{\circ} \mathrm{C}$. In the ex-vivo study of several transdermal patches, patch C [SD of MET: HP $\beta C D$ (1:5)] showed the controlled release and permeation of drug.

Conclusion: Poor solubility of new chemical entities being a well known problem for past few decades despite the imbalance between significant research efforts \& few successful marketed formulations, the solid dispersion proves to hold a key position among all the various formulation strategies to enhance the aqueous solubility \& dissolution rate and thereby the bioavailability of poorly aqueous solubility of drug.

Keywords: Bioavailability, DSC, Metoclopramide hydrochloride, solid dispersion, HP $\beta C D$,

Article Info: Received 01 Oct, 2018; Review Completed 02 Nov 2018; Accepted 06 Nov 2018; Available online 15 Nov 2018

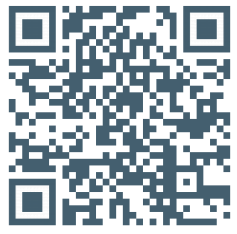

Cite this article as:

Mukhopadhyay G, Mukhopadhyay R, Mukhopadhyay A, Kundu S, Banerjee S, Manna D, Sarkar A, Nazar T, Sarkar S, Bala S, Formulation Development to Enhance the Solubility of Metoclopramide Base Drug by Solid Dispersion and Evaluation of Transdermal Film, Journal of Drug Delivery and Therapeutics. 2018; 8(6):183-191 DOI: http://dx.doi.org/10.22270/jddt.v8i6.2039

*Address for Correspondence:

Dr Goutam Mukhopadhyay, Associated Professor, Department of Pharmaceutical Technology, BCDA College of Pharmacy \& Technology, 78, Jessore Road(S), Kolkata-700127.

List of abbreviations

API

MET

M.W.

M.P.

HP $\beta C D$

PVP

PLX
Active Pharmaceutical Ingredients

Metoclopramide

Molecular Weight

Melting Point

Hydroxypropyl-Beta-Cyclodextrin

Polyvinyl pyrrolidone

Poloxamer
SD

DSC

NCE

$\mathrm{K}_{\mathrm{C}}$

$\Delta \mathrm{G}$

$\Delta \mathrm{H}$

$\Delta \mathrm{S}$
Solid Dispersion

Differential Scanning Calorimetry

New chemical entities

Complexation constant

Gibbs free energy change

Enthalpy change

Entropy change 


\section{INTRODUCTION}

Drug development process plays an important role in achieving scientific success and commercial launching of drug product. The study of solubility is of important concern to improve dissolution rate, bioavailability of drug and to control drug release and to achieve desired therapeutic responses for a prolong period of time.Now-adays, in drug discovery, the main motto has been to produce more and more compounds that exhibit high lipophilicity and poor water solubility. Such physicochemical characteristics lead to problematic biopharmaceutical properties which in turn diminish the likelihood success in the clinic. The principle objective of dosage form design is to achieve a predictable therapeutic response to a drug included in a formulation which is capable of large scale manufacture with reproducible product quality.Many of new API emerging out of throughput and combinatorial screening tools are under great challenge owing to their poor aqueous solubility and dissolution rate. Morethan 40\% NCEs (new chemical entities) developed in pharmaceutical industries are practically insoluble in water.Therefore drug solubility enhancement is major challenge for formulation scientist. Various techniques are used for the enhancement of solubility of poorly soluble drugs which includes physical \& chemical modification of drug, particle size reduction, crystal engineering, salt formation, solid dispersion, use of surfactant, complexation and so forth.

The rationale of this present investigation was to prepare solid dispersion (SD) of Metoclopramide in base form (M.W.-299.8) with various carriers to enhance its aqueous the solubility by solid dispersion technique and to compare the solubility in various types of aqueous media and its use in preparation of transdermal film. In this method Metoclopramide base and carrier (i.e. HP $\beta C D$, Polaxamer 188 and PVP K-30) were dispersed in the mixture of ethanol \& dichloromethane to produce a clear solution by stirring in a magnetic stirrer at room temperature and subsequently upon the removal of solvent, solid powder was obtained. The present study includes the determination of the solubility of SD products \& phase solubility study of binary systems with carriers in order to investigate the cause of solubilisation\& characterization of various solid dispersion products.

Enhancement of solubility of poorly water sloluble drug by solid dispersion technique attributed to particle size reduction, improved wettability and dispersibility, higher porosity, decreased lattice energy, amorphous state 1 .

The dispersion of an active ingredient in an inert hydrophilic carrier at solid form prepared by fusion, solvent evaporation technique is defined as solid dispersion. Solid dispersions (SDs) traditionally have been used as an effective method to improve the dissolution properties and bioavailability of poorly water-soluble drugs ${ }^{2}$. Solid dispersion has attracted considerable interest as an effective means of improving the dissolution rate and the bioavailability. Solid dispersion systems have been realized as extremely useful tool in improving the dissolution properties of poorly soluble drugs ${ }^{3}$. The first drug whose rate and extent of absorption was significantly enhanced using the solid dispersion technique was sulfathiazole 4

Metoclopramide is chemically 4-amino-5-chloro- $\mathrm{N}-[2-$ (diethylamino) ethyl]-2-methoxybenzamide, an antiemetic and gastroprokinetic agent. It is commonly used to treat nausea and vomiting to facilitate gastric emptying in people with gastroparesis and as a treatment of gastric stasis often associated with migraine headache. The molecular formula of Metoclopramide is $\mathrm{C}_{14} \mathrm{H}_{22} \mathrm{ClN}_{3} \mathrm{O}_{2}$, which corresponds to a molecular weight of 299.8 \& its melting point is $147^{\circ} \mathrm{C}$. Metoclopramide is basically soluble in ethanol \& practically insoluble in ether. Its aqueous solubility is $200 \mathrm{mg} / \mathrm{L}$ at $25^{\circ}$ C.It is absorbed well after oral administration but a significant first pass effect in some human patients may reduce systemic bioavailability to $30 \%$. There apparently is a great deal of interpatient variation with this effect. Bioavailability after intramuscular administration has been measured to be 74$96 \%$. After oral dosing peak plasma levels generally occur within 2 hours. The drug is well distributed in the body and enters the CNS. Metoclopramide is only weakly bound to $13-22 \%$ of plasma proteins. Metoclopramide is primarily excreted in the urine in humans approximately $20-25 \%$. The majority of the rest of the drug is metabolised to glucuronidated or sulfated conjugate forms and then excreted through urine. Approximately $5 \%$ is excreted in the faeces. The half life of Metoclopramide in the dog has been reported to be approximately 90 minutes.

Metoclopramide is basically a Dopamine-2 receptor antagonist. Metoclopramide exerts its prokinetic effect by antagonizing dopamine mediated relaxation effect on gastrointestinal smooth muscle. This enhances the response of gastrointestinal smooth muscle to cholinergic stimulation and thereby leading to an increase of gastric emptying into the intestines. It antagonizes D2 dopamine receptors in chemoreceptive trigger zone (CTZ) of medulla and thereby preventing nausea and vomiting. Metoclopramide also decreases reflux into the oesophagus by increasing the resting pressure of the lower oesophageal sphincter and improves acid clearance from oesophagus by increasing amplitude of oesophageal peristaltic contractions. A study showed that high dose of Metoclopramide antagonizes 5-hydroxytryptamine (5HT) receptors in the peripheral nervous system in animals.

To achieve a desired release and therapeutic response to a drug included in the formulation is always preferable. So, after enhancing the solubility and dissolution rate of poorly soluble drugs, the development of dosage form is often necessary to achieve the desired release pattern and effective therapeutic response. Therefore, to achieve as well as to maintain the drug concentration within the therapeutically effective range, the prepared MET base solid dispersion was developed as a transdermal drug delivery system using controlled release polymer and 3M backing layer membrane. Topical \& transdermalproducts remain key formulation for drugs to the skin for systemic action 5 . In order to asses permeability of drug through skin transdermal patches were formulated by without MET HCl drug and polymers, MET base drug and polymers, SD of MET:HP $\beta C D$ and polymers, SD of MET:PVP K30 and polymers and SD of MET:PLX-188.

\section{MATERIALS USED}

\section{Polymers used:}

$>$ Hydroxypropyl- $\beta$-cyclodextrin (HP $\beta C D$ ) [Tokyo Chemical Industries Co.Ltd.]

$>$ Polyvinyl pyrolidone (PVP K30)[LobaChemie,Mumbai]

$>$ Poloxamer-188[Sigma Chemicals]

$>$ Ethyl cellulose[Sigma Aldrich Chemicals]

$>$ Hydroxypropyl Methylcellulose or Hypromellose (HPMC)[Colorcon Asia Pvt.Ltd,GAO,INDIA]

Drug used: Metoclopramide HCL (M.P:-147º , M.W:-299.8 $\mathrm{g} / \mathrm{mol}$ ) [Yarrow chemicals] 


\section{Reagent used:}

$>$ Potassium dihydrogen phosphate (Merck specialities Pvt. Ltd., Mumbai),

$>$ Sodium hydroxide (Merck specialities Pvt. Ltd., Mumbai),

$>$ Sodium chloride (Qualikems Fine Chemicals Pvt. Ltd., New Delhi).

\section{Solvent used:}

* Acetone(Quest Chemicals, Kolkata),

* Methanol(SpectrochemPvt. Ltd.,Mumbai),

- Dichloromethane (Merck specialities Pvt. Ltd.,Mumbai),

* Ethanol(obtained from the departmental store of BCDA college of Pharm. Tech.),

- Double distilled water (obtained from the lab of Pharmaceutical Engineerining of BCDA college of Pharm. Tech.),

* Phosphate buffer pH7.4.

Plasticizer used: Dibutyl phthalate (Merck specialities Pvt. Ltd., Mumbai)

Backing Layer: Gifted by 3M Drug Delivery, USA.

\section{APPARATUS}

* Metal applicator: Stain less steel 316, length $9 \mathrm{~cm}$, breadth $2 \mathrm{~cm}$, height $11 \mathrm{~cm}$, width of gap for film casting $150,250,350,500 \mu$.

* Franz diffusion cell was fabricated by Remco (local glass blower), height, internal diameter, outer diameter and volume of receptor cell are $11 \mathrm{~cm}$ for both (receptor cell and donor cell), $2 \mathrm{~cm}$ (internal diameter of donor cell) and $50 \mathrm{ml}$ respectively. Both ends of donor cell (elongated tube) are open; diameter of external opening is $2.5 \mathrm{~cm}$. Receptor cell is jacketed externally for water circulation.

\section{INSTRUMENTS}

* UV-Visible spectrophotometer (ANALAB, UV-180).

* Water bath (Integrated electrolife system by SUNBIM)

* Magnetic stirrer (Trason, multispins) and REMI (2MLH, magnetic stirrer).

\section{METHODS}

\section{Conversion of Metoclopramide hydrochloride to Metoclopramide base form:}

Metoclopramide is available in hydrochloride form (aqueous soluble) in the market. Therefore for sake of the research it is converted from hydrochloride form to Metoclopramide.

4gm of Metoclopramide hydrochloride was dispersed in the sufficient double distilled water followed by stirring until the total amount of drug gets fully dissolved. The solution is neutralized by $1 \mathrm{M}$ sodium hydroxide solution \& gradually a precipitate was formed and the precipitate was collected by filtration (Whatman filter paper grade 1) and the precipitate thus obtained was washed several times with double distilled water to remove HCL which was produced during precipitation.Thereafter the wet precipitate was dried in hot air oven at $50^{\circ} \mathrm{C}$. Afterward the solid material was cooled up to room temperature $\left(25^{\circ} \mathrm{C}\right)$ and was treated with acetone in order to make a saturated solution and stirred continuously at $50^{\circ} \mathrm{C}$. Then the solution was allowed to attain room temperature \& thereafter it was kept in refrigerator and crystal particles of Metoclopramide (base form) was formed and collected.
The material was cooled at room temperature and it was weighed and its melting point was determined.

\section{Preparation of Calibration Curve:}

In order to prepare the calibration curve, $10 \mathrm{mg}$ of drug (metoclopramide base) was actually weighed and dissolved in known volume of methanol $(\sim 3 \mathrm{ml})$ and finally the rest of the volume was adjusted with aqueous phase (DDW, Phosphate buffer $\mathrm{pH} 7.4$ ) up to $100 \mathrm{ml}$. A series of dilution were made form stock solution $(2-20 \mu \mathrm{g} / \mathrm{ml}$ concentration) for each buffers and assayed under UV-spectrophotometer (ANALAB and model of UV-180) at the wave length of $272 \mathrm{~nm}$ and the average absorbance data of three observations were plotted against dilutions. The linear curve for phosphate buffer pH7.4, DDW, Phosphate buffer $\mathrm{pH} \quad 6.8 \quad \& \mathrm{pH} \quad 1.2 \quad$ buffer showed $\quad\left(\mathrm{R}^{2}=0.999\right.$, $Y=0.049 x+0.018),\left(R^{2}=0.999, \quad Y=0.049 x+0.009\right),\left(R^{2}=0.999\right.$, $\mathrm{Y}=0.044 \mathrm{x}+0.003) \quad \& \quad\left(\mathrm{R}^{2}=0.9997, \quad \mathrm{Y}=0.0324 \mathrm{x}+0.0077\right)$ respectively. Thus the unknown concentration of Metoclopramide is estimated.

\section{Preparation of solid dispersion (SD) by solvent evaporation technique:}

Solid dispersion prepared from hydrophilic polymers using the solvent evaporation technique is effective in improving drug dissolution. Solvent evaporation method was carried out by dispersing a physical mixture of drug and polymer at certain ratio in a common solvent and then it was evaporated until a transparent solvent free thin layer of mass was obtained. Then the film was dried till constant weight at $50^{\circ} \mathrm{C}^{6}$.

\section{Characterisation of solid dispersion formulation:}

Characterization of solid dispersion was performed by the instrumental analysis like Differential Scanning Calorimetry (DSC) analysis.

\section{Differential scanning calorimetry(DSC) analysis:}

DSC analysis is mainly carried out for metoclopramide loaded solid dispersion, physical mixture \& also for pure drug to analyze the crystallinity and amorphous nature of compounds. The analysis was carried out in Pyri's diamond TG/DTA; P, Perkins Elmer Instruments) supported by a thermal analyzer. Under the nitrogen flow of $150 \mathrm{ml} / \mathrm{min}$, approximately $10 \mathrm{mg}$ of sample (Metoclopramide base, polymer substances and solid dispersions) was placed in a sealed aluminium pan and heated at scanning rate of $10^{\circ} \mathrm{C} /$ min over the temperature of $30^{\circ} \mathrm{C}-300^{\circ} \mathrm{C}$.

\section{Determination of aqueous solubility of drug:}

Aqueous solubility study was performed by taking excess amount of metoclopramide in an aqueous phase (phosphorous buffer pH 7.4, DDW, phosphate buffer pH 6.8 and $\mathrm{pH} 5.5$ buffers) and shaken at $37^{\circ} \mathrm{C}, 40^{\circ} \mathrm{C}, 45^{\circ} \mathrm{C}$ respectively and observed after $24 \mathrm{hr}$ to obtain solubility.

\section{Dissolution Study:}

Dissolution study of Metoclopramide was performed in (Yarrow Chem. Products, Phosphorous buffer pH 7.4 with $0.9 \% \mathrm{NaCl}$, USP rotating paddle II type) dissolution apparatus under sink condition at $37 \pm 0.5^{\circ} \mathrm{C}$ and $50 \mathrm{rpm}$. A sample of solid dispersion equivalent to $10 \mathrm{mg}$ of metoclopramide was used in each test. Samples were withdrawn at distinct time intervals and absorbance was absorbed at $\lambda_{\max }$ of $272 \mathrm{~nm}$ using UV-visible spectrophotometer. 


\section{Phase solubility analysis:}

The phase solubility study is carried out to determine binding/complexation constant $\left(\mathrm{K}_{\mathrm{c}}\right)$ of polymer -drug complexes. These complexes effectively modify the solubility characteristics of drug. Phase solubility study was performed by dissolving known amount of polymers with increasing amount to each of series of test tubes containing aqueous phase (phosphate buffer pH 7.4, DDW). Thereafter excess amount of drug was added to each of the tube shaken for $24 \mathrm{hrs}$ at $25^{\circ}, 37^{\circ}, 40^{\circ} \& 45^{\circ} \mathrm{C}$ respectively. After $24 \mathrm{hr}$ very slight quantity of insoluble material was observed at the bottom of each test tube and then the content of each test tube was filtered and the filtrate was collected and its absorbance was recorded and $\mathrm{K}_{\mathrm{a}}$ was calculated.

\section{Fabrication of transdermal patch:}

Patch was fabricated with the prepared formulations containing the polymers ethyl cellulose, HPMC, PVP K30 at different composition in addition with known amount of dibutyl phthalate as plasticizer and liquid blend as cast on the $3 \mathrm{M}$ backing layer membrane by a metal applicator. The different Patchesare:

- $\quad$ Patch A: HPMC(50mg)+EC(100mg)+PVPK30 (100mg)

- Patch B: HPMC(50mg)+EC(100mg)+PVPK30

$(100 \mathrm{mg})+$ MET base pure $\operatorname{drug}(100 \mathrm{mg})$

- Patch C: HPMC(50mg)+EC(100mg)+PVPK30 $(100 \mathrm{mg})+\mathrm{SD}$ of MET-HP $\beta C D(1: 5)$ [equivalent to $100 \mathrm{mg}]$

- $\quad$ Patch D: HPMC(50mg)+EC(100mg)+PVPK30 (100mg)+SD of MET-PLX-188(1:5) [equivalent to $100 \mathrm{mg}]$

- $\quad$ Patch E: HPMC(50mg)+EC(100mg)+PVPK30 (100mg)+SD of MET-PVP K30 (1:5)

- Patch F: HPMC(50mg)+EC(100mg)+PVPK30 $(100 \mathrm{mg})+\mathrm{MET} \mathrm{HCl}$ (100mg drug)

\section{Ex-vivo permeation study:}

Ex-vivo permeation study was done by using excised ear part of pig followed by the removal of external debris. After cleaning a part of ear it was mounted between the donor and receptor compartment of Franz diffusion cell (gas apparatus). The receptor portion contains aqueous phase (phosphate buffer pH 7.4 with $0.9 \% \mathrm{NaCl}$ ). Permeation study was carried out using pure drug and solid dispersion formulations in the donor cells which is in contact with the dorsal part of ear skin. Concentration of the drug $(1 \mathrm{mg} / \mathrm{ml}$ and $5 \mathrm{mg} / \mathrm{ml}) /$ solid dispersion was maintained with solvent (ethyl alcohol \& phosphate buffer pH 7.4 with $0.9 \%$ $\mathrm{NaCl}$ ) in the donor cells. Samples of permeate was collected at the intervals of 30 minutes at a constant temperature $37^{\circ} \mathrm{C}$ and replaced immediately by equal amount of fresh aqueous phase. Then the collected samples are analyzed in spectrophotometer at $272 \mathrm{~nm}$.

\section{In vitro diffusion study:}

In vitro diffusion study was carried out by using Franz diffusion cell. The Franz diffusion cell has a receptor compartment of approximately $50 \mathrm{ml}$ and effective surface area of diffusion/ permeation was $3.14 \mathrm{~cm}^{2}$. The study was conducted in two steps:

i. At first the diffusion of the drug from the transdermal patch was studied. Patch was attached between donor and receptor cell and samples were withdrawn from liquid (phosphate buffer $\mathrm{pH}$ 7.4) of receptor cell at intervals and drug amount present in the samples was determined by observing the absorbance.

ii. Secondly, diffusion of drug and simultaneous permeation of drug through the porcine ear skin was studied. The ear portion of pig was duly excised and external debris was removed by treating with phosphate buffer $\mathrm{pH} 7.4$ for half an hour. Then excised skin was placed in between donor and receptor compartment and a weighed extent of transdermal patch was fixed on the dorsal side of the skin. The receptor cell was filled up with phosphate buffer $\mathrm{pH}$ 7.4 and its content was stirred by a magnetic bar placed inside the cell. Temperature of receptor cell was maintained at $37 \pm 0.5^{\circ} \mathrm{C}$ by circulating the water trough the external jacketed path. Water was supplied by a constant temperature water bath.Franz diffusion cell was placed on a multi cell magnetic stirrer. Samples were withdrawn at intervals and replaced by equal amount of fresh buffer and the samples as collected were analyzed in a spectrophotometer at wave length of $272 \mathrm{~nm}$.

\section{Determination drug content (\%) of film:}

Drug content analysis was evaluated by taking $2 \mathrm{ml}$ of methanol followed by addition of 1 square centimetre of different patches and stirred with a magnetic stirrer. Then DDW was slowly added \& diluted up to $100 \mathrm{ml}$ in a volumetric flask. Then the solution was filtered and the content of drug was determined by UV Spectrophotometer. Blank solution was made by the blank patch (patches without drug).

\section{RESULTS\& DISCUSSION}

\section{- Determination of $\lambda_{\max }$ of Metoclopramide:}

$\lambda_{\max }$ of Metoclopromide base was determined first by scanning the solution of Metoclopromide in UV spectrophotometer. $\lambda_{\max }$ of Metoclopromide was found to be $272 \mathrm{~nm}$.

\section{- Preparation of standard curve:}

The standard curve was prepared by plotting absorbance against concentration of individual analyst. The calibration graph was found to be a linear in concentration range of 2$20 \mu \mathrm{g} / \mathrm{ml}$ in double distilled water (DDW) at pH 7.4, pH 6.8 and $\mathrm{pH} 1.2$. 
Table 1: Absorbance of metoclopramide at $272 \mathrm{~nm}$ for different concentrations in DDW \& in pH 7.4

\begin{tabular}{|c|c|c|c|}
\hline \multirow{11}{*}{$\begin{array}{c}\text { Absorbance in } \\
\text { DDW }\end{array}$} & Serial no. & Concentration $(\mu \mathrm{g} / \mathrm{ml})$ & Absorbance at $272 \mathrm{~nm}$ \\
\hline & 1. & 2 & 0.113 \\
\hline & 2. & 4 & 0.2112 \\
\hline & 3 & 6 & 0.3056 \\
\hline & 4. & 8 & 0.411 \\
\hline & 5. & 10 & 0.5112 \\
\hline & 6. & 12 & 0.615 \\
\hline & 7. & 14 & 0.7142 \\
\hline & 8. & 16 & 0.8174 \\
\hline & 9. & 18 & 0.9032 \\
\hline & 10. & 20 & 0.9964 \\
\hline \multirow{11}{*}{$\begin{array}{l}\text { Absorbance in } \\
\text { pH } 7.4\end{array}$} & Serial no. & Concentration $(\mu \mathrm{g} / \mathrm{ml})$ & Absorbance at $272 \mathrm{~nm}$ \\
\hline & 1. & 2 & 0.112 \\
\hline & 2. & 4 & 0.2138 \\
\hline & 3 & 6 & 0.3142 \\
\hline & 4. & 8 & 0.4016 \\
\hline & 5. & 10 & 0.525 \\
\hline & 6. & 12 & 0.6106 \\
\hline & 7. & 14 & 0.7078 \\
\hline & 8. & 16 & 0.7992 \\
\hline & 9. & 18 & 0.9014 \\
\hline & 10. & 20 & 0.995 \\
\hline
\end{tabular}

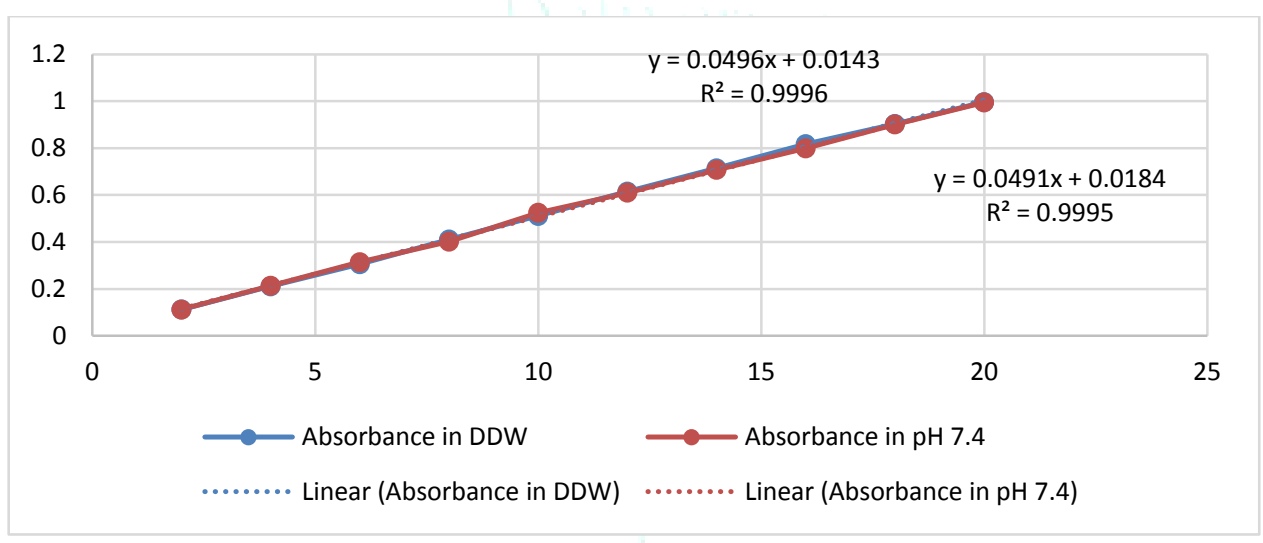

Figure 1: Standard curve in DDW \& in pH 7.4

Table 2: Absorbance of Metoclopramide at 272nm for different concentrations in pH 6.8 \& in pH 1.2

\begin{tabular}{|c|c|c|c|}
\hline \multirow{11}{*}{$\begin{array}{l}\text { Absorbance in } \\
\text { pH } 6.8\end{array}$} & Serial no. & Concentration $(\mu \mathrm{g} / \mathrm{ml})$ & Absorbance at $272 \mathrm{~nm}$ \\
\hline & 1. & 2 & 0.0924 \\
\hline & 2. & 4 & 0.185 \\
\hline & 3 & 6 & 0.2728 \\
\hline & 4. & 8 & 0.3638 \\
\hline & 5. & 10 & 0.4466 \\
\hline & 6. & 12 & 0.5462 \\
\hline & 7. & 14 & 0.635 \\
\hline & 8. & 16 & 0.7232 \\
\hline & 9. & 18 & 0.82144 \\
\hline & 10. & 20 & 0.8926 \\
\hline \multirow{11}{*}{$\begin{array}{l}\text { Absorbance in } \\
\text { pH } 1.2\end{array}$} & Serial no. & Concentration $(\mu \mathrm{g} / \mathrm{ml})$ & Absorbance at $272 \mathrm{~nm}$ \\
\hline & 1. & 2 & 0.0722 \\
\hline & 2. & 4 & 0.137 \\
\hline & 3 & 6 & 0.2066 \\
\hline & 4. & 8 & 0.265 \\
\hline & 5. & 10 & 0.3298 \\
\hline & 6. & 12 & 0.4006 \\
\hline & 7. & 14 & 0.4548 \\
\hline & 8. & 16 & 0.5236 \\
\hline & 9. & 18 & 0.593 \\
\hline & 10. & 20 & 0.6584 \\
\hline
\end{tabular}




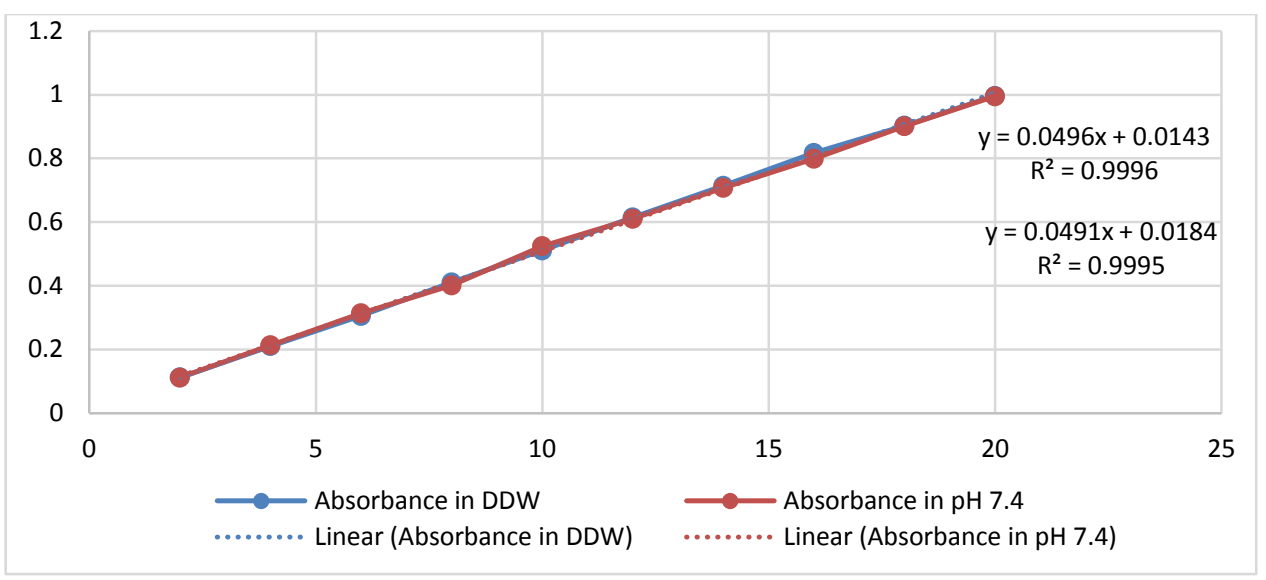

Figure 2: Standard curve in pH 6.8 \& pH 1.2

Table 3: Study of aqueous solubility of binary solid dispersion of Metoclopramide with various carriers at $37^{\circ} \mathrm{C}$

\begin{tabular}{|l|l|l|l|l|}
\hline Binary system & $\mu \mathrm{g} / \mathrm{ml}$ in DDW & $\mu \mathrm{g} / \mathrm{ml}$ in $\mathrm{pH} 7.4$ & $\mu \mathrm{g} / \mathrm{ml} \mathrm{in} \mathrm{pH} 6.8$ & $\mu \mathrm{g} / \mathrm{ml} \mathrm{in} \mathrm{pH} 5.5$ \\
\hline HP 0:1 & 191.83 & 1367.6 & 3363.6 & 553.2 \\
HP 1:1 & 202.04 & 1448.9 & 3727.3 & 8085.1 \\
HP 2:1 & 353.06 & 1836.7 & 4386.3 & 14680.8 \\
HP 3:1 & 483.67 & 2469.4 & 5727.3 & 22340.4 \\
\hline PVP 0: 1 & 191.83 & 1346.9 & 3363.6 & 5553.2 \\
PVP 1:1 & 383.67 & 1734.7 & 3772.7 & 10212.7 \\
PVP 2:1 & 489.79 & 2224.5 & 4454.5 & 15744.7 \\
PVP 3:1 & 602.04 & 2918.3 & 6181.8 & 21914.9 \\
\hline PLX 0:1 & 191.83 & 1346.9 & 3363.6 & 8723.4 \\
PLX 1:1 & 204.08 & 1612.2 & 3863.6 & 15957.4 \\
PLX 2:1 & 212.24 & 1918.3 & 4727.3 & 18936.2 \\
PLX 3:1 & 232.65 & 2714.3 & 6409.1 & 22978.7 \\
\hline
\end{tabular}

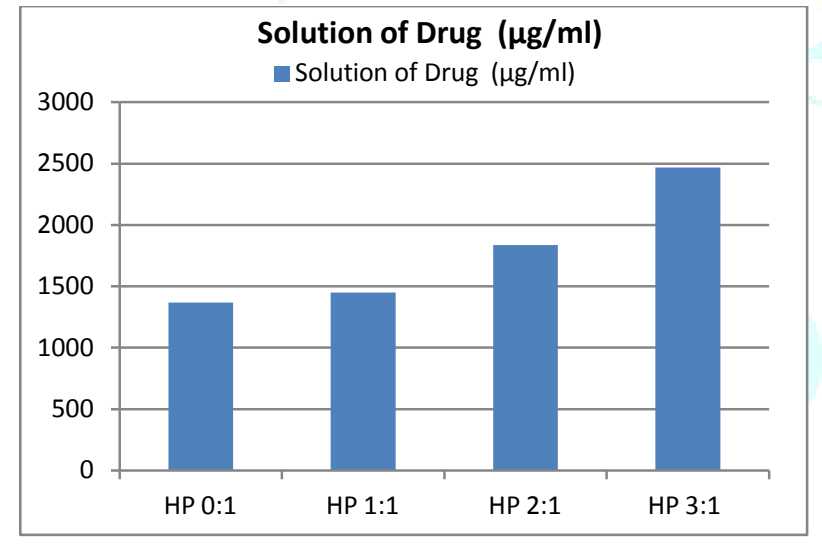

Figure 3: Effect of carrier (HPßCD) drug ratio of SD on the solubility of MET. In DDW

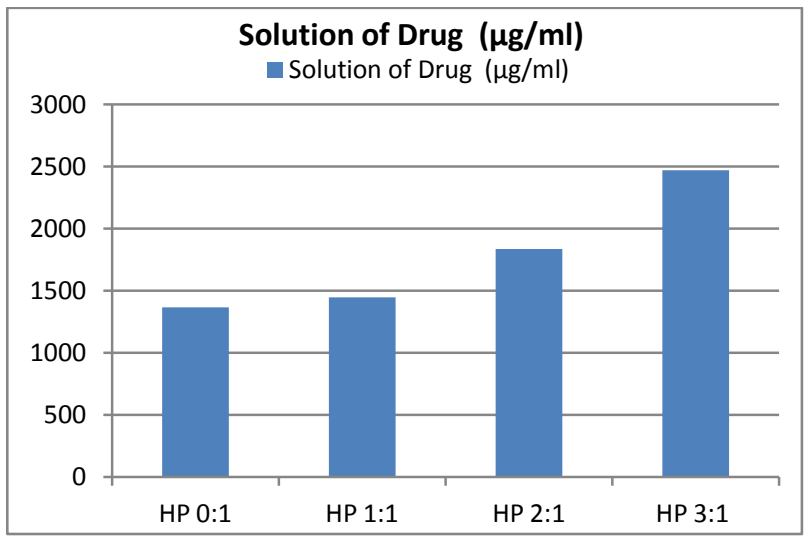

Figure 4: Effect of carrier (HPßCD) drug ratio of SD on the solubility of MET. In pH 7.4

\section{- Study of aqueous solubility of solid dispersion at} $37^{\circ} \mathrm{C}$

In the above Fig3 \& Fig4, Table3, the saturation solubility of Metoclopramide with various carriers was shown. Metoclopramide is sparingly soluble $(191.83 \mu \mathrm{g} / \mathrm{ml})$ in double distilled water (DDW). Its aqueous solubility increases linearly keeping the drug amount fixed when fraction of carrier substance (HP $\beta C D$ ) in solid dispersion of drug is increased. Solubility of pure Metoclopramide increases in acidic pH. In pH 5.5 (solubility is $5553.2 \mu \mathrm{g} / \mathrm{ml})$, pH6.8 (3363.3 $\mu / \mathrm{ml}), \mathrm{pH} 7.4(1367.3 \mu \mathrm{g} / \mathrm{ml})$ which are higher than that of the solubility in DDW $(191.8 \mu \mathrm{g} / \mathrm{ml})$ at $37^{\circ} \mathrm{C}$. After comparing various data of solubility it is observed that the solubility of drug in $\mathrm{pH} 5.5$ is $28.95(=5553.2 / 191.8)$ times greater than that of pure drug in DDW in samples without any carrier substances.

In the medium of DDW, enhancement of solubility of SDHP $\beta C D$ drug $(5: 1)$ is 4.55 times more than that of pure drug. In acidic medium (pH 5.5), enhancement is very high ( $\sim 97$ and $\sim 27$ times) in comparison with that of the pure drug in DDW and SD in DDW respectively when ratio is $10: 1$.

In case of Poloxamer effect (50.67 times) was higher. In case of PVP K-30 drug solubility enhancement in DDW was lesser in comparison with that of HP $\beta C D$. Its solubility increases with the enhancement of amount of carrier in SD.

\section{- Dissolution study of solid dispersion:}

Dissolution of solid dispersion (5:1) in two medium was performed. In DDW the Cumulative \% dissolution is found

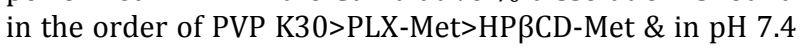
it is in the order of PLX-Met>PVP K30>HP $\beta C D-$ Met.Dissolution study of SD of HP $\beta C D$ : MET (5:1) in four different media is performed and observed that the 


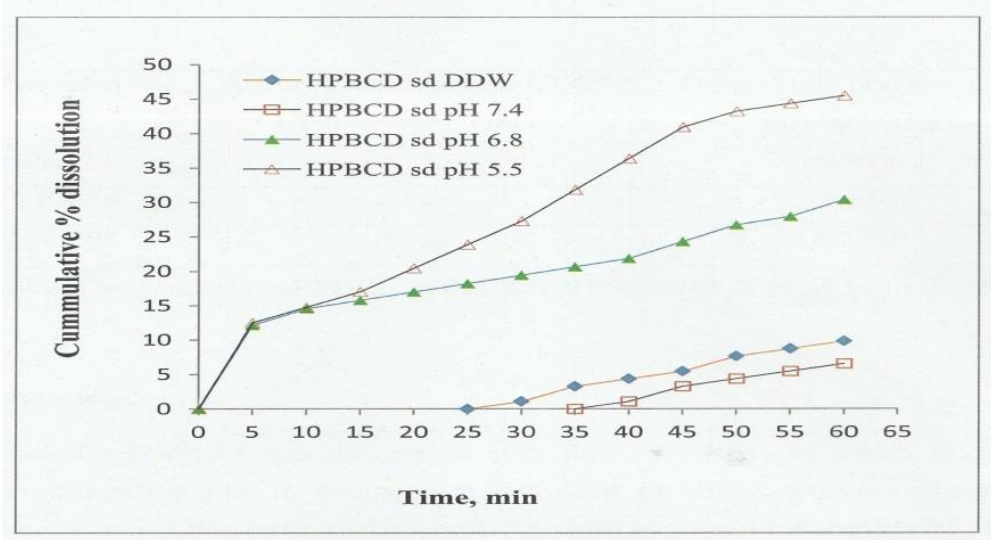

Figure 5: Effect of pH on MET: HPßCD-SD (1:5) of different dissolution media on rate of dissolution.

\section{- Drug content of solid dispersion products:}

Various binary combination of MET-solid dispersion was prepared with different carriers such as HPßCD, PVP K30and PLX-188 by solvent evaporation technique. In the table 4 the data of drug content were shown.HB $\beta C D$ have the ability to enhance the solubility by the complex formation ${ }^{7}$. Hydroxy propyl - $\beta$-cyclodextrin is a hydroxyl alkyl derivative of $\beta c d \&$ has a wide application increasing the field of drug solubility because of its inclusion ability along with its high water solubility ${ }^{8}$. In case of water soluble polymers PVP K30 and PLX-188, the solubility of MET was enhanced with increasing amount of carrier substances in each medium.

Table 4: Drug content of MET: HP $\beta C D / P V P$ K30/PLX (1:5) solid dispersion

\begin{tabular}{|l|l|l|}
\hline Polymer & $\begin{array}{l}\text { Absorbance in media DDW } \\
{[\mathrm{Y}=0.049 \mathrm{x}+0.009]}\end{array}$ & $\begin{array}{l}\text { Drug }(1 \mu \mathrm{g}) \text { present in SD } \\
\text { products }(\mu \mathrm{g})\end{array}$ \\
\hline HP $\beta C D$ & 0.775 & 6.473 \\
\hline PVP K30 & 0.745 & 6.658 \\
\hline PLX-188 & 0.860 & 5.7579 \\
\hline
\end{tabular}

\section{- Phase solubility study:}

The study of Phase solubility was performed with three different carriers at different temperature and from the slope and the intercept of solubility curves the binding constants \& thermodynamic parameters such as change of free energy $(\Delta G)$, change of enthalpy $(\Delta H)$ and change of entropy $(\Delta S)$ was calculated. Free energy change of these binary combinations was found negative which indicates spontaneous solubilisation. Free energy change varies from $\sim-9$ to $15 \mathrm{KJ} / \mathrm{mol}$ which suggests that the drug may bind with the carrier molecules which are held by weak physical forces like Vander Waals force, Hydrogen bonding and some hydrophobic forces.

The effect of temperature (298-318K) on $\mathrm{K}_{\mathrm{c}}$ in $\mathrm{pH} 7.4$ was much prominent in each binding in comparison with that of $\mathrm{pH} 7.4$ and DDW.With the rise of temperature the mobility of ionic species of MET in acidic $\mathrm{pH}$ increases which in turn, possibly inhibits complex formation with the carriers. At the higher temperature, the intrinsic solubility of the drug increased while the stability constants are found low. Stability constant is lowered with the decreased of $\mathrm{pH}$ in $(\mathrm{pH} 7.4>\mathrm{pH} 5.5)$ each system. The degree of dissociation of MET increases with the decrease of $\mathrm{pH}$ so the $\mathrm{K}_{\mathrm{c}}$ value decreases in acidic $\mathrm{pH}$ due to less interaction between ligand and guest molecules ${ }^{9}$.

The entropy change $(\Delta \mathrm{S})$ was found negative in $\mathrm{pH} 5.5$ \& positive in higher $\mathrm{pH}$. Negative entropy change and low $\mathrm{K}_{\mathrm{c}}$ values in acidic pH 5.5 may be explained as ligand molecules are more ionized at $\mathrm{pH} 5.5$ and water molecules are comparatively more ordered.

Higher $\mathrm{K}_{\mathrm{c}}$ values for the MET-PVP K30 AND CV-PLX 407 systems are observed in comparison with that of the systems with MET-HP $\beta C D$ and as a result MET-PVPK30 \& MET-PLX 180 system showed a low solubility than that of other carrier.

\section{- DSC Analysis:}

Differential scanning calorimetry confirms about crystalline or amorphous nature of compounds. DSC thermogram of Metoclopramide base showed a sharp endothermic peak at its melting point $\left(147^{\circ} \mathrm{C}\right)$ which exhibits in crystalline form complying with that of Metoclopramide hydrochloride form, melting point was found to be $85^{\circ} \mathrm{C}$. DSC thermogram of physical mixture (drug: carrier $=$ Metoclopramide base: $\operatorname{HP} \beta C D=1: 5$ ) had showed a small endothermic peak similar to that of Metoclopramide base. Thermograms of solid dispersion (drug:HP $\beta C D \quad=1: 5$ ) revealed disappearance of endothermic peak of Metoclopramide base corresponding to its melting point due to its uniform homogeneous dispersion within the drug and carrier, amorphization by overcoming crystal lattice energy and subsequent binding by hydrogen bond within the amorphous carrier HP $\beta C D$. 


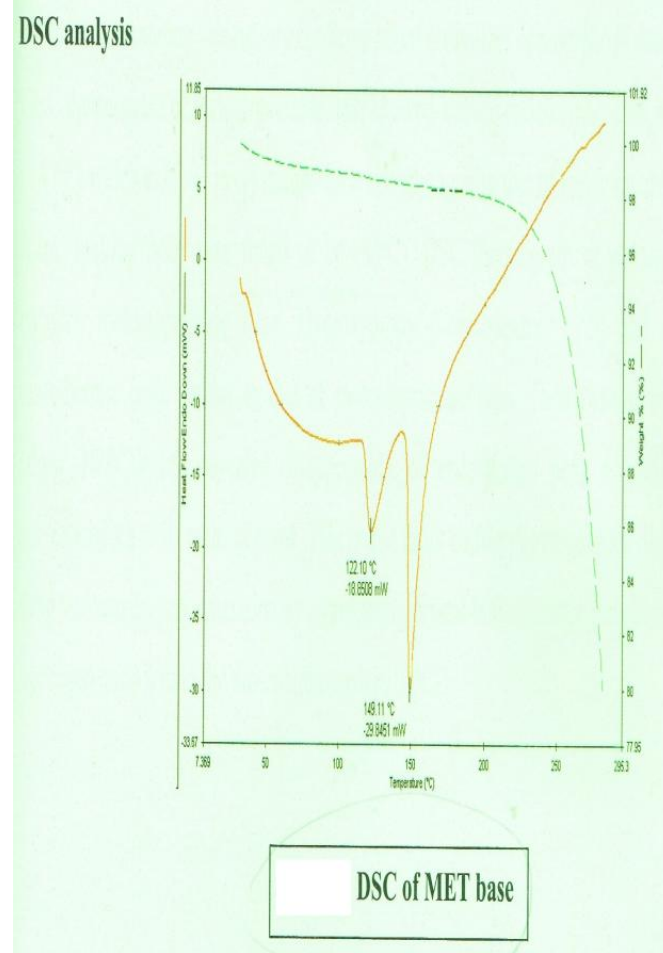

Figure 6: DSC of MET base.

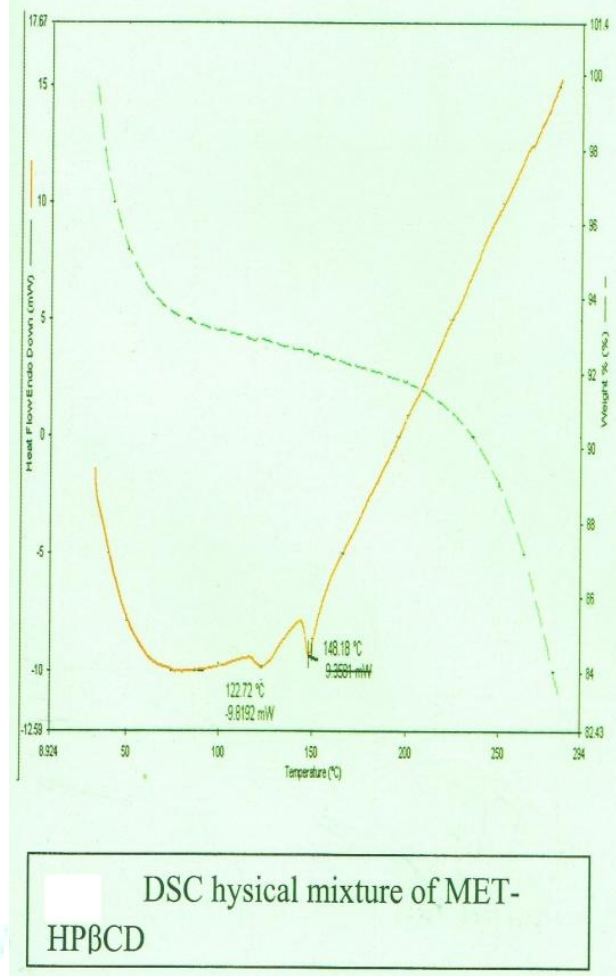

Figure 7: DSC hysical misture of MET- HP $\beta C D$.

Table 5: Binding constants \& thermodynamic function for the interaction of MET base with various carriers in different $\mathrm{pH}$ mediums at different temperatures

\begin{tabular}{|c|c|c|c|c|c|c|c|}
\hline \multirow[t]{2}{*}{ Carriers } & \multirow{2}{*}{$\begin{array}{l}\text { Temp. } \\
\text { In } \\
\text { Kelvin }\end{array}$} & \multicolumn{2}{|c|}{ Medium, DDW } & \multicolumn{2}{|c|}{ Medium, pH 7.4} & \multicolumn{2}{|c|}{ Medium, pH 5.5} \\
\hline & & $\mathrm{K}_{\mathrm{a}}(\mathrm{M}-1)$ & $\begin{array}{l}\Delta \mathrm{G}, \Delta \mathrm{H}, \Delta \mathrm{S} \\
(298-318) \mathrm{K}\end{array}$ & $\mathrm{K}_{\mathrm{a}}(\mathrm{M}-1)$ & $\begin{array}{l}\Delta \mathrm{G}, \Delta \mathrm{H}, \Delta \mathrm{S} \\
(298-318) \mathrm{K}\end{array}$ & $\mathrm{K}_{\mathrm{a}}(\mathrm{M}-1)$ & $\begin{array}{l}\Delta \mathrm{G}, \Delta \mathrm{H}, \Delta \mathrm{S} \\
(298-318) \mathrm{K}\end{array}$ \\
\hline \multirow[t]{3}{*}{ PVP-K30 } & 298 & 95.71968 & $\begin{array}{l}\Delta \mathrm{G}=-11.301 \\
\Delta \mathrm{H}=26.600 \\
\Delta \mathrm{S}=0.127\end{array}$ & & & & \\
\hline & 310 & 145.0439 & $\begin{array}{l}\Delta \mathrm{G}=-12.331 \\
\Delta \mathrm{H}=237.479 \\
\Delta \mathrm{S}=0.838\end{array}$ & & & & \\
\hline & 313 & 350.7873 & $\Delta \mathrm{G}=-14.519$ & & & & \\
\hline \multirow[t]{4}{*}{ HP $\beta C D$} & 298 & 81.57048 & $\begin{array}{l}\Delta \mathrm{G}=-10.905 \\
\Delta \mathrm{H}=-10.391 \\
\Delta \mathrm{S}=0.0017\end{array}$ & 73.9589 & $\begin{array}{l}\Delta \mathrm{G}=-10.6623 \\
\Delta \mathrm{H}=-12.196 \\
\Delta \mathrm{S}=-0.0052\end{array}$ & 61.35846 & $\begin{array}{l}\Delta \mathrm{G}=-10.1995 \\
\Delta \mathrm{H}=-19.0854 \\
\Delta \mathrm{S}=-0.0298\end{array}$ \\
\hline & 310 & 69.34625 & $\begin{array}{l}\Delta \mathrm{G}=-10.5027 \\
\Delta \mathrm{H}=-7.884 \\
\Delta \mathrm{S}=0.0087\end{array}$ & 61.1273 & $\begin{array}{l}\Delta \mathrm{G}=-10.1902 \\
\Delta \mathrm{H}=-5.8992 \\
\Delta \mathrm{S}=0.014399\end{array}$ & 45.5377 & $\begin{array}{l}\Delta \mathrm{G}=-9.4607 \\
\Delta \mathrm{H}=-9.8532 \\
\Delta \mathrm{S}=-0.00132\end{array}$ \\
\hline & 313 & 67.34263 & $\begin{array}{l}\Delta \mathrm{G}=-10.430 \\
\Delta \mathrm{H}=-6.4624 \\
\Delta \mathrm{S}=0.0133\end{array}$ & 59.8008 & $\begin{array}{l}\Delta \mathrm{G}=-10.1358 \\
\Delta \mathrm{H}=-10.5123 \\
\Delta \mathrm{S}=-0.00126\end{array}$ & 43.8993 & $\Delta \mathrm{G}=-9.3699$ \\
\hline & 318 & 64.76378 & $\Delta \mathrm{G}=-10.333$ & 56.1206 & $\Delta \mathrm{G}=-9.97483$ & 41.6846 & \\
\hline \multirow[t]{3}{*}{ PLX-188 } & 298 & 444.9036 & $\begin{array}{l}\Delta \mathrm{G}=-15.108 \\
\Delta \mathrm{H}=-5.3565 \\
\Delta \mathrm{S}=0.0327\end{array}$ & & & & \\
\hline & 310 & 409.185 & $\begin{array}{l}\Delta \mathrm{G}=-14.900 \\
\Delta \mathrm{H}=-42.277 \\
\Delta \mathrm{S}=-0.0918\end{array}$ & & & & \\
\hline & 313 & 349.6546 & $\begin{array}{l}\Delta \mathrm{G}=-14.511 \\
\Delta \mathrm{H}=-77.528 \\
\Delta \mathrm{S}=-0.2114\end{array}$ & & & & \\
\hline
\end{tabular}




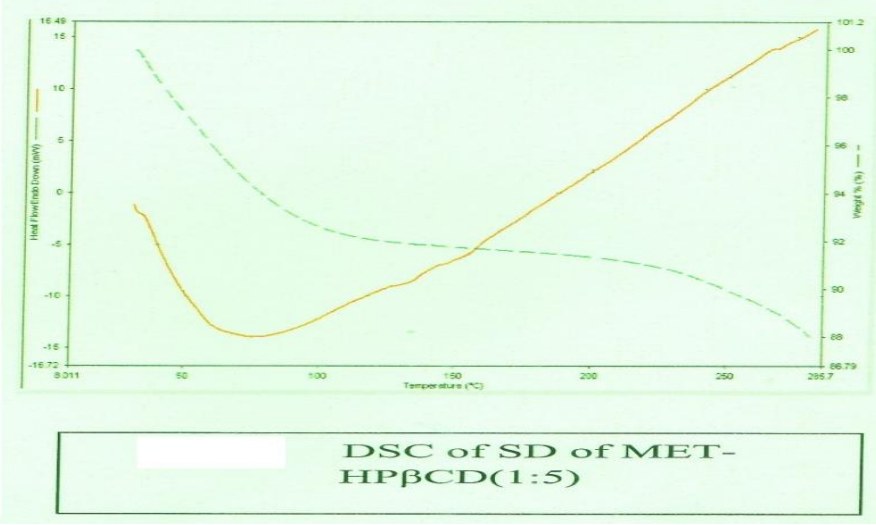

Figure 8: DSC of SD of MET- $\operatorname{HP} \beta C D(1: 5)$

\section{- Ex-vivo Permeation Study of Patches:}

Table 6: Ex-vivo permeation study of MET pure drug and its solid dispersions.

\begin{tabular}{|c|c|c|c|c|c|}
\hline SL.No. & Permeation Experiment Code & $\begin{array}{l}\text { Average slope } \\
(\mu \mathrm{g} / \mathrm{min})\end{array}$ & SL.No. & $\begin{array}{l}\text { Permeation Experiment } \\
\text { Code }\end{array}$ & $\begin{array}{l}\text { Average slope } \\
(\mu \mathrm{g} / \mathrm{min})\end{array}$ \\
\hline 1. & A1 (1mg, ET), Pure drug & 4.316 & 1. & A3(1mg,PBS),Pure drug & 3.443 \\
\hline 2. & B2 (5mg, ET), Pure drug & 3.453 & 2. & B3(5mg,PBS),Pure drug & 4.143 \\
\hline 3. & C1 (1mg, ET), HP $\beta C D-S D$ & 4.506 & 3. & C3(1mg,PBS),HP $\beta C D-S D$ & 2.120 \\
\hline 4. & D1 (5mg, ET), HP $\beta C D-S D$ & 5.073 & 4. & D3(5mg,PBS), HP $\beta C D-S D$ & 5.107 \\
\hline 5. & E1 (1mg,ET),PLX-SD & 3.923 & 5. & E3(1mg,PBS),PLX-SD & 1.630 \\
\hline 6. & F1 (5mg, ET), PLX-SD & 5.976 & 6. & F3(5mg,PBS),PLX-SD & 5.930 \\
\hline 7. & G1 (1mg,ET), PVP K30-SD & 5.113 & 7. & G3(1mg,PBS),PVP K30-SD & 2.935 \\
\hline 8. & H1 (5mg,ET), PVP K30-SD & 5.450 & 8. & H3(5mg,PBS),PVP K30-SD & 4.718 \\
\hline
\end{tabular}

[Drug /SD dissolved in ET(ethanol 96\%), PBS-Phosphate buffer pH 7.4, 1 mg-1 mg/ml, $\mathbf{5 ~ m g - 5 m g / m l ] ~}$

The ex-vivo study of transdermal patch C [SD of MET: HP $\beta C D(1: 5)]$ showed the controlled release and permeation. And SD of MET: PLX-188 (1:5) [Patch D] was permeating slowly through the skin, Patch B \& Patch E showed higher permeation but not controlled release permeation at a time.

\section{CONCLUSION}

Poor solubility of new chemical entities is a well known problem for past few decades.Despite the imbalance between significant research efforts \& few successful marketed formulations, the solid dispersion proves tobe a key position among all the various formulation strategies to enhance the aqueous solubility \& dissolution rate and thereby the bioavailability of drug. The solid dispersion of drug prepared with $\mathrm{HP} \beta C D$ by solvent evaporation technique showed a better dissolution rate in $\mathrm{pH} 7.4$ and solubility $1367.3 \mu \mathrm{g} / \mathrm{ml}$ in $\mathrm{pH} 7.4$.

The dissolution rate \& solubility of the prepared solid dispersions were improved when compared with that of pure drug due to conversion of drug from crystalline to amorphous nature and formation of complexation between drug and hydrophilic carriers. The result of experiment reveals that the preparation of MET solid dispersion with HP $\beta C D$ by solvent evaporation method is promising approach to improve the solubility and dissolution rate of MET base.

\section{Acknowledgement:}

The authors are highly thankful to BCDA College of Pharmacy \& Technology, Barasat for providing all the facilities to carry out the research work successfully.

\section{Conflict Of Interest:}

The authors have none to declare.

\section{REFERENCES}

1. DQM Craig, The mechanism of drug release from solid dispersion in water soluble polymers, Int.J.Pharm, 2002; 231:131144.

2. Md. Howlader SI, Charabarty JK et al. Enhancing dissolution profile of diazepam using using hydrophilic polymer by solid dispersion technique. International current pharmaceutical journal, 2012; 1(12):423-430.

3. Dhirendra K, Lewis S, Udupa $\mathrm{N}$ et al, Solid dispersion: A review, 2009; 1(2):234-246.

4. Kumar B.P., Enhancement of dissolution rate of Efavirenz by solid dispersion technique. J. Pharm. Res, 2001; 1(4):025-049

5. Michale E. Aulton, Kevin M.G. Taylor, Aulton's Pharmaceutics, The design \& manufacture of medicines, $4^{\text {th }}$ edition.

6. Mogal S A, Gurjar P N, Yamgar D S et al. Solid dispersion technique for improving solubility of some poorly soluble drugs, Scholars research library, 2012; 4(5):1574-1586.

7. Santos C, Buera MP, Mazzobre MF, Phase solubility studies of terpineol with $\beta$-cyclodextrins and stability of the freeze-dried inclusion complex, International Congress on Engineering and Food, 2011; 1:355-362.

8. Misiuk W, Zalewska M, Investigation of inclusion complex of trazodone hydrochloride with hydroxypropyl- $\beta$-cyclodextrin, Carbohydrate polymer, 2009; 77(3):482-488.

9. Domańska U., Pelczarska A., Pobudkowska A., Effect of 2hydroxypropyl- $\beta$-cyclodextrin on solubility of sparingly soluble drug derivatives of anthranilic acid, International Journal of Molecular Sciences, 2011; 12:2383-2394. 